\title{
(U]
}

Revista Mexicana de Derecho Constitucional

Núm. 40, enero-junio 2019

\section{El juez humanista: el nuevo guardián del derecho en el paradigma neoconstitucional}

\section{The Humanist Judge: The New Guardian of the Right in the Paradigm Neoconstitucional}

\section{María Belén REDONDO*}

RESUMEN: Los cambios vertiginosos que trajo consigo el fenómeno de mundialización de los derechos humanos impulsaron una apertura semántica del concepto de derecho. Esto conllevó a que no sólo comenzara a diferenciarse el "derecho" de la "ley", sino también el modo de interpretar las normas. Es así que se produjo el pasaje del Estado constitucional al actual Estado democrático de derechos humanos regido por el paradigma neoconstitucional. A partir de este pasaje, las esferas del Estado fueron amoldándose a los nuevos requerimientos. El rol del juez también se vio modificado, porque ahora su dirección del proceso deberá garantizar la tutela judicial efectiva, concepto elástico y progresivo. Es así que deberá tener en cuenta todas las aristas que se proyectan del derecho de acceso a la justicia en forma de derechos y principios, y que permiten la flexibilización de las normas para resolver el caso particular de modo humanizado.

Palabras clave: neoconstitucionalismo; humanidad; justicia; derechos humanos.
ABSTRACT: The dizzying changes that brought the phenomenon of globalization of human rights prompted an opening semantics of the concept of law. This led to that not only will begin to differentiate the "right" of the "law", but also how to interpret the rules. Thus, there was the passage of the Constitutional State to the current Democratic State of Human Rights governed by the paradigm neoconstitucional. From this passage, all areas of the State were settling in to the new requirements. The judge's role was also modified, because now his leadership of the process should ensure effective legal protection, elastic and progressive concept. It is thus that must take into account all the edges that are projected the right of access to justice in the form of rights and principles, and that allow the relaxation of rules to resolve the particular case so humanized. Keywords: Neoconstitutionalism; Humanity; Justice; Human Rights. 
SUMARIO: I. Introducción. II. El rol del juez en el pasaje del Estado monárquico al Estado democrático de los derechos humanos. III. El valor "justicia" como eje central del Estado democrático de derechos humanos. IV. Los paradigmas en la resolución de casos. V. El nuevo paradigma de la decisión: "el juez humanista integrativista”. VI. El juez decide, el corazón guía. VII. Conclusión.

\section{INTRODUCCIÓN}

El pasaje del Estado de derecho constitucional al Estado democrático neoconstitucional, o Estado de derechos humanos, a causa de la internalización de los derechos fundamentales, nos invita a repensar las estructuras institucionales con el objeto de dar garantía a lo proclamado por el derecho internacional de los derechos humanos.

Hoy entendemos que los tres poderes del Estado (el Legislativo, el Judicial y el Ejecutivo) deben coordinar sus acciones y asumir roles activos para que toda la actividad estatal tienda a la real efectivización de los derechos.

El Poder Legislativo deberá abrir el ordenamiento jurídico para crear normas que reconozcan derechos y sus correspondientes mecanismos de garantización, a fin de que respondan eficientemente a la solución de los conflictos sociales, ya que en reiteradas oportunidades la doctrina ha expresado que "nada sirve si los derechos están consagrados, pero no existen las vías idóneas para efectivizarlos". 1

El Poder Ejecutivo, por su parte, deberá posicionarse con políticas públicas que cristalicen el principio material de igualdad, superando aquel concepto de igualdad formal, y activando una especial protección para aquellos que se encuentran en una condición de vulnerabilidad. ${ }^{2}$

1 Redondo, María Belén, "Tutela preventiva en el paradigma del juez humanista integrativista", Disertación en el II Encuentro de la Doctrina Procesal, preparatorias del IV Encuentro Anual de la FAEP y preparatorias del XXVIII Congreso Nacional de Derecho Procesal, Corrientes, marzo de 2015.

2 Véase a profundidad el análisis de todas las categorías de sujetos en condición de vulnerabilidad en Redondo, María Belén, 100 Reglas de Brasilia sobre el acceso a la justicia de las personas en condición de vulnerabilidad. Comentadas; concordadas con CPCCSF; leyes complementarias; acordadas; jurisprudencia provincial; nacional y de la CIDH; derecho comparado, Rosario, Juris, 2015. 
El rol del Poder Judicial, sin embargo, será determinante en esta tarea conjunta, ya que, una vez que llegue un caso a sus puertas, deberá resolverlo ajustando el "ser" con el "deber ser", salvaguardando las falencias del sistema, y haciendo del valor "justicia" el eje central de sus decisiones. ${ }^{3}$ Es decir, el juez, como cara visible del sistema de justicia, deberá remover, con las herramientas que cuente, todos los obstáculos existentes, con el objeto de materializar las exigencias del derecho internacional de los derechos humanos.

Para lograr su cometido, "el Juez en su nuevo rol recurre a nuevos principios jurídicos que permiten flexibilizar los principios clásicos y brindar de esta manera respuestas más humanitarias". ${ }^{4}$

\section{EL ROL DEL JUEZ EN EL PASAJE DEL ESTADO MONÁRQUICO AL ESTADO DEMOCRÁTICO DE LOS DERECHOS HUMANOS}

El pasaje de un modelo de Estado al otro ha sido el fruto de numerosos cambios que se han dado en la historia de la humanidad en función del binomio Estado-derechos. El quiebre de paradigmas representa las crisis sufridas en un determinado momento de la historia, en donde se hace eco el agotamiento del modelo vigente y la necesidad de buscar una vía que dé respuestas a las nuevas exigencias.

Asimismo, los cambios de paradigmas producen, en términos de Thomas Khun, una revolución copernicana en el rol que desempeñan los diferentes actores estatales, entre los que encontramos el cambio en el papel que desempeñan los jueces.

De este modo, en función del modelo de Estado, los magistrados cumplirán con uno u otro rol con relación a las exigencias propias del modelo vigente y de lo que la sociedad necesite, tal y como se verá en los próximos apartados.

Es así que, en un primer momento, nos encontramos con el paradigma del Estado monárquico: el absolutismo era el modelo imperante en el antiguo régimen, donde existía la figura del rey como máxima autoridad y la población era considera súbdita de él.

3 Redondo, María Belén, "Derecho de acceso a la justicia de personas en condiciones de vulnerabilidad: aplicación y efectividad de las 100 Reglas de Brasilia”, Diplomatura Avanzada en Derechos Humanos, Universidad de Alcalá de Henares-CLADH, 2018.

4 Redondo, María Belén, "El debido proceso en el neoconstitucionalismo", Revista e-universitas. UNR Journal, año 8, vol. 1, noviembre de 2015. 
Este sistema rígido de poder dio lugar a numerosos abusos donde reinaban la desigualdad social y los altos impuestos, lo cual provocó un gran descontento popular.

Aquella parte de la sociedad denominada "burguesa" comenzó a tomar fuerza y a reclamar condiciones más igualitarias, y es así que en el siglo XIX ésta se levanta contra el poder imperante de la época, produciéndose la Revolución francesa, y, de este modo, se da paso al surgimiento del llamado Estado liberal.

En este sentido, se ha dicho que

La concentración de poderes en manos del monarca soberano, útil para la defensa del territorio y protección del comercio de su nación frente a terceros, con frecuencia se transformaría en un Estado represor como medio para asegurar la sumisión de los pueblos. Ello se prolongaría por siglos hasta que por la acción de la sociedad, elementalmente organizada y poco informada, debió ceder su espacio y diluirse para dar paso a un Estado comprometido con los ciudadanos: el Estado-nación. ${ }^{5}$

El Estado comienza a ceder poco a poco su soberanía al pueblo, y el objetivo del pueblo se vuelve el de imponer límites al poder de aquél. Además, el rol del juez, en este momento histórico, era el de asegurar la libertad y la propiedad individual sin interpretación de la ley, más que aquella que surgía del texto mismo. Tal y como lo decía la Escuela de la exégesis: debido a la gran desconfianza que se le tenía al Poder Judicial, no se le permitía al magistrado juzgar según las reglas de la equidad; el juez era tan sólo "la boca de la ley".

El siglo XIX es el llamado siglo del Estado de derecho; en él subyacía la idea de existencia de una soberanía interna, considerando al Estado como ente superior a cualquier otro sujeto, y desde lo externo no admitía supeditarse a una autoridad superior, es decir, no reconocía ni órganos supranacionales ni Estados superiores.

La doctrina ha reconocido que este Estado de derecho fue presupuesto indispensable para la construcción del Estado constitucional, al que se dio lugar con posterioridad.

5 Iturraspe Oviedo, Francisco José et al., América Latina: Estado Derecho en la era de la Mundialización, Aportes para el debate académico jurídico y político, Caracas, Editorial Académica Española, 2012, p. 86. 
Si bien todos los Estados, por estar dotados de un ordenamiento jurídico, podían denominarse "de derecho", lo cierto es que el concepto de derechos fundamentales empezó a cobrar importancia, pasando a un segundo plano el Estado como eje central, y la ley, la cual era concebida como un instrumento emanado de la voluntad del Estado, comenzó a pensarse como una herramienta que debía garantizar derechos a la sociedad.

Podemos decir que este Estado de derecho se basó primordialmente en el principio de legalidad, el cual “...expresa la idea de la ley como acto normativo supremo e irresistible al que, en línea de principio, no es oponible ningún derecho más fuerte, cualquiera que sea su forma y fundamento..." ${ }^{6}$ El apego al principio de legalidad colocaba al Poder Legislativo como el poder sobre el que se estructuró toda la actividad estatal.

Frente al temor de aquel poder despótico y absolutista, en este modelo de Estado se denota una sumisión a la ley del resto de las fuentes del derecho, $\mathrm{y}$, en este sentido, los jueces se encontraban constreñidos a aplicar las normas de manera rigurosa sin poder hacer interpretaciones que excedan la letra de la ley.

De este modo, "en la soberanía legislativa estaba ínsita la fuerza normativa absoluta, pero también el deber de asumir por entero el peso de todas las exigencias de regulación". ${ }^{7}$ Con ello, en este modelo de Estado no sólo estaba vigente el principio de legalidad, sino también el de igualdad formal, funcional al objetivo de eliminar aquellas distinciones que habían impuesto las antiguas monarquías. En otras palabras:

El Estado de derecho es enemigo de los excesos, es decir, del uso "no regulado" del poder. La generalidad de la ley comporta una "normatividad media", esto es, hecha para todos, lo que naturalmente contiene una garantía contra un uso desbocado del propio poder legislativo... La generalidad de la ley era, en fin, garantía de la imparcialidad del Estado respecto a los componentes sociales, así como de su igualdad jurídica. ${ }^{8}$

Sin embargo, esa igualdad formal entra en crisis cuando la ley, por ser tan general, deja de lado distinciones importantes para resolver los conflictos de sus ciudadanos. Es así que comienza a darse paso al estado Consti-

6 Zagrebelsky, Gustavo, El derecho dúctil. Ley, derechos, justicia, Madrid, Trotta, 1995 , p. 24.

7 Ibidem, p. 25.

8 Ibidem, p. 29. 
tucional, en donde la ley “...viene sometida a una relación de adecuación, y por tanto de subordinación, a un estrato más alto de derecho establecido por la Constitución". ${ }^{9}$

De este modo, el derecho constitucional europeo reconoció un "«patrimonio de derechos», originario, independiente y protegido frente a la ley", ${ }^{10}$ asemejándose a las ideas constitucionales norteamericanas, lo que, por ejemplo, se refleja en la Declaración de Derechos de Virginia de 1776, reconociendo a los derechos como la base y el fundamento del gobierno.

Estas declaraciones han consagrado la teoría de que existe una esfera jurídica que es precedente a cualquier legislador, y así se ha dicho que "los derechos eran un patrimonio subjetivo existente por sí mismo que debía mantenerse inalterado y protegido de todas las posibles amenazas...". ${ }^{11}$ Es decir, dada la existencia de un núcleo de derechos fundamentales, éstos debían ser consagrados en la Constitución como documento trascendental y fundante del Estado.

Siguiendo con esta idea, los derechos no sólo son preexistentes al Estado, sino también a la Constitución, constituyéndose, de esta manera, los individuos como sujetos originarios que delegaban el poder para crearla, fundando así el Estado y, dentro de él, el Poder Legislativo.

En este sentido, los jueces controlan que sus sentencias se redacten conforme a esa esfera de derechos fundamentales que están contemplados en las Constituciones, es decir, se ocupan de mantener la supremacía de la Constitución por encima de las leyes.

Ahora bien, con la sanción de la Ley de Bonn y el juzgamiento de los crímenes de Núremberg, se da apertura a una nueva etapa, donde se reconoce la existencia del Estado en función de la sociedad y no al revés.

Y es así que comienza a hacerse la distinción entre "derecho" y "ley", y el ordenamiento reconoce su propia elasticidad para alcanzar aquella tan anhelada igualdad material.

De este modo, "la primera de las grandes tareas de las constituciones contemporáneas consiste en distinguir claramente entre la ley, como regla establecida por el legislador, y los derechos humanos, como pretensiones subjetivas absolutas, válidas por sí mismas con independencia de la ley". ${ }^{22}$

\footnotetext{
9 Ibidem, p. 34.

10 Ibidem, p. 54.

11 Idem.

12 Ibidem, p. 47.
} 
En la segunda mitad del siglo XX cobra auge la teoría neoconstitucional como nuevo paradigma del Estado de democrático de derecho, que toma como punto de partida al Estado constitucional, pero lo supera, ya que su naturaleza teórico-práctica deja entrever su misión, que es la de integrar los derechos fundamentales reconocidos con sus respectivas garantías, además de ocuparse de la esfera de la efectividad ${ }^{13}$ de la decisión judicial en su fase ejecutoria.

Por su parte, también podemos agregarle a la definición de la teoría neoconstitucional que se constituye en una

...teoría [que] se avoca a la expansión de las fuentes del derecho, y pretende explicar la integración del Derecho internacional de los Derechos Humanos en el orden interno de los diversos estados. Pero no sólo ello, sino que también el Neoconstitucionalismo pretende promover soluciones legislativas, ejecutivas y judiciales que logren una tutela real de los Derechos Humanos, para acortar la brecha entre el ser y el deber ser. ${ }^{14}$

Es decir, el modelo de Estado constitucional, que se ocupó de la consagración de aquel núcleo de derechos fundamentales como forma de limitar el poder del Estado, entró en crisis, porque el foco se trasladó al principio de utilidad.

En este sentido, ya nos hemos hecho la pregunta: ¿de qué vale tener derechos reconocidos si no se pueden efectivizar? Así, la esfera de la efectividad de los derechos se vuelve un eje central y, con ello, el rol que los jueces asumen en este paradigma.

Pero cuando hablamos de derechos reconocidos no sólo se hace alusión a aquellas facultades y garantías que los Estados han internalizado en sus ordenamientos jurídicos, sino que cuando hablamos de derechos, valores y principios de derechos humanos se alude a todo un sistema reconocido por la comunidad jurídica internacional.

De este modo, comienza a gestarse en la conciencia de los Estados de que existe una comunidad internacional que no sólo reconoce derechos fun-

13 Redondo, María Belén, "Tutela preventiva y el nuevo rol del juez humanista integrativista", Zeus On Line, 10 de julio de 2015, disponible en: http://www.zeus.com.ar/ umTexto.asp? id $=1231 \&$ materia $=9 \&$ nocache $=1489713040000$ (fecha de consulta: 5 de septiembre de 2018).

14 Redondo, María Belén, "Perspectivas de la violencia de género en la era de la teoría neoconstitucional como el nuevo paradigma del derecho internacional de los derechos humanos", Revista Universitas, núm. 28, 2018, pp. 38-58. 
damentales pertenecientes a todos los seres humanos por el hecho de ser tales, y que no pueden violarse con normas contrarias sancionadas en el derecho interno, ${ }^{15}$ sino que además ejerce una función de control y expectativa de que esos derechos sean respetados.

Hablamos, entonces, no de un Estado de derecho, sino de un Estado democrático de derechos, donde la ductilidad del derecho permite alcanzar la justicia del caso concreto a través de numerosas herramientas, como pueden ser los principios que se desprenden de los derechos humanos, los valores que protegen, y un derecho que surge no sólo de la ley, sino también de las sentencias dictadas por la Corte Interamericana de Derechos Humanos, vinculantes por el reconocimiento de su competencia supranacional al haber sido ratificada la Convención Americana sobre Derechos Humanos por los Estados parte.

Asimismo, se produce una reformulación del concepto de soberanía, "el cual comprende los términos: supremacía e independencia, la primera hace referencia a que el Estado no admite un poder superior, y la segunda, implica estar reconocido en la comunidad internacional como sujeto de derecho". ${ }^{16}$ Ahora, los Estados encuentran sometida su soberanía a las decisiones de la Corte Interamericana de Derechos Humanos.

Dentro de las cuestiones fundamentales que dieron paso a este nuevo modelo, tenemos a la de fijar principios de justicia a través de normas constitucionales para que rigieran todo el ordenamiento jurídico, reconociendo que hay un orden superior que está por encima de las voluntades particulares y atiende a los intereses generales.

Los principios se basan así en los valores más importantes que protege toda la sociedad en su conjunto y que los magistrados deben de tener en cuenta a la hora de dictar sentencia.

En este sentido, podemos decir que el fenómeno de mundialización de los derechos humanos implicó un pasaje del paradigma del Estado constitucional al paradigma de Estado democrático neoconstitucional o de derechos humanos, en el que nos encontramos actualmente, donde la promoción de los derechos fundamentales, junto a sus correspondientes garantías, se

15 Redondo, María Belén, "Programa Constitucional y Derechos Humanos", Revista Al Día Argentina, 2014, disponible en: http://ar.microjuris.com/arJurisAdvSearch.jsp (fecha de consulta: 2 de septiembre de 2018).

16 Redondo, María Belén, "El rol del Poder Judicial en la era de la globalización", Revista Al Día Argentina, 2014, disponible en: http://ar.microjuris.com/arJurisAdvSearch. jsp (fecha de consulta: 2 de septiembre de 2018). 
vuelve la misión principal, valiéndose para ello de nuevas herramientas que provienen principalmente del derecho internacional de los derechos humanos, modificando los estándares internos acerca de qué se considera como justo.

Los jueces tienen la misión no sólo de realizar el control de constitucionalidad, sino que también ahora deben mantener la supremacía convencional, puesto que de no hacerlo se podría incurrir en responsabilidad internacional del Estado por incumplimiento de sus obligaciones convencionales.

Con ello, en esta nueva etapa, los administradores de justicia deben conocer en profundidad lo dispuesto por los derechos humanos y hacerlo efectivo, pero demás deberán pone un especial énfasis cuando se trata de personas en condición de vulnerabilidad.

Por su parte, un sujeto en condición de vulnerabilidad puede ser definido como

...aquel que debido a una cualidad intrínseca de su persona encuentra una restricción mayor que la del resto de la población para defender sus derechos, ya sea al momento de la apertura de la instancia judicial como durante la tramitación del juicio, y que por lo tanto, obliga a los operadores de justicia a aplicar las reglas del proceso de una manera activa, para que al entrar en contacto con la justicia la persona no sufra una doble vulnerabilidad, menoscabando derechos fundamentales y causando un daño irreparable. ${ }^{17}$

Los magistrados se convierten así en los jueces Hércules, del que ya hablaba Dworkin, es decir, aquellos que buscan la mejor y única respuesta que le cabría para el caso concreto, por cuanto tienen en cuenta las circunstancias particulares que refieren a lo subjetivo y a los elementos específicos.

Ya no se atienen a reproducir la letra de la ley, sino que son jueces activistas, que interpretan en función de los derechos humanos y que buscan dar cumplimiento con lo dispuesto por el derecho de acceso a la justicia en todas sus vertientes.

De este modo, el derecho en forma de caso judicial llega también a todo el continente americano, ceñido de sus propias particularidades, pero con un objetivo mundial consensuado: efectivizar los derechos mediante el ofrecimiento de vías eficaces e idóneas para hacerlo posible.

17 Redondo, María Belén, "Derechos humanos y acceso a la justicia, una mirada neoconstitucional”, Revista Electrónica Iberoamericana, vol. 9, núm. 2, 2015. 


\section{EL VALOR “JUSTICIA" COMO EJE CENTRAL DEL ESTADO DEMOCRÁTICO DE DERECHOS HUMANOS}

Lo que se exige de los jueces hoy es que sus sentencias sean justas; si bien es un valor que todos asumimos desde siempre y que debe cristalizarse en las decisiones judiciales, actualmente se proclama como eje en el nuevo Estado democrático de derecho.

Este Estado democrático de derechos humanos puede ser definido como un modelo de Estado que cede parte de su soberanía al participar en la comunidad jurídica internacional, asumiendo compromisos multilaterales que reconocen la competencia de tribunales internacionales como últimos en la pirámide jurídica para decidir sobre cuestiones relativas a los derechos humanos, y, en consecuencia, ejercen un control sobre la responsabilidad internacional de los Estados ante incumplimientos de origen convencional.

El objeto de este Estado democrático de derechos humanos será integrar los derechos fundamentales con sus correspondientes garantías $\mathrm{y}$, en caso de violaciones a estos derechos, positivizar todas las vías idóneas necesarias para la reparación de esta situación.

Así, también dentro de su objeto se encuentra la de internalizar los avances que se produzcan en materia de derechos humanos, pues estamos frente a conceptos elásticos y progresivos ${ }^{18}$ que, a su vez, operan con principios jurídicos internacionales, como el pro homine y el ius cogens.

Goldschmidt nos dice que "La justicia es un valor. Los valores, a su vez, son entes ideales... Los entes ideales abarcan aquella parte de la realidad que es sólo asequible a la razón". ${ }^{19}$

La justicia en las sociedades constituye un valor central; ésta califica una conducta, un acto, una regla, y hasta utilizamos esa palabra para calificar a las personas. Para determinar que permite caracterizar a un acto como justo o injusto, debemos establecer previamente los criterios que la sociedad aprueba o no, lo que para ella vale. Por supuesto, al intentar definir los criterios nos encontramos con un concepto dúctil y con diferentes concepciones acerca de lo que es. Podemos decir que la justicia es un acto

18 Redondo, María Belén, "Concepto de derechos humanos”, Red Internacional de Derechos Humanos (próximo a publicarse el video educativo), Ginebra, 2018.

19 Goldschmidt, Werner, Introducción filosófica al derecho. La teoría trialista del mundo jurídico y sus horizontes, 6a. ed., Buenos Aires, Depalma, 1996, p. 369. 
voluntario, es decir, realizado con intención, libertad y discernimiento, que aparecerá cuando se ejecute en cumplimiento con una regla.

Aristóteles relacionaba la justicia con el peso, la medida o ciertos cálculos. El resultado va a ser justo porque está basado en alguno de estos instrumentos que son exactos, y nadie discute su exactitud; para este maestro griego, lo justo es lo equitativo. Por su parte, Santo Tomás aconseja recurrir a la equidad y no aplicar la ley que sea defectuosa.

Sin embargo, hoy los jueces encarnan el derecho vivo y dinámico, que no sólo contempla la aplicación de silogismos; el magistrado se sirve de todo ese sistema jurídico para hacer justicia y su decisión será considerada válida en la medida en que respete el contenido de los derechos fundamentales.

Para Montesquieu, la positividad de las leyes refleja las relaciones preexistentes entre las personas, por lo que el legislador no crea normas que contemplan la equidad, ya que éstas son naturales, sino que las tomó de la realidad que se venía dando y las codificó. Contrariamente, Hume expresaba que las reglas de justicia son construcciones humanas, por ende artificiales, y que están fundadas en la utilidad.

Del Vecchio ${ }^{20}$ ha dicho que

La justicia exige que todo sujeto sea reconocido y tratado por los demás como un principio absoluto de sus propios actos. La justicia exige que, en el trato recíproco, se tome en consideración esta identidad metaempírica de naturaleza y que se excluya, en consecuencia, toda disparidad no fundada sobre el modo de ser y de obrar efectivo de cada uno, debiéndose, pues, considerar todo comportamiento según una misma medida absoluta.

En este sentido, también se ha dicho que "El agente justo, hombre o divinidad, se define por lo común como aquél que se esmera en lograr decisiones justas o conocer las reglas justas. La justicia del agente constituye, en ese supuesto, una virtud derivada y no la fuente de toda justicia". ${ }^{21}$

En la concepción judeocristiana se dice que Dios es justicia, misericordia, rectitud, solidaridad, compasivo, y que ama a la justicia; en efecto, será justo el que confíe en Dios y observe sus mandamientos, pero lo será, sobre todo, aquel cuyo corazón sea recto, $\mathrm{y}$, por último, también será justo aquel que imite la justicia divina.

\footnotetext{
20 Kelsen, Hans, Crítica del derecho natural, Madrid, Taurus, 1966, p. 175.

21 Ibidem, p. 179.
} 
En la teoría del derecho natural, el derecho positivo será justo en la medida en que sea conforme a aquél, por lo que una norma positiva injusta no podrá considerarse válida.

Para Platón, la justicia era la virtud fundamental y armonizadora de la estructura social, y la forma de gobierno debe expresarla como un equilibrio comparable al alma humana, para que lo inferior se supedite a lo superior y se produzca entonces el traslado del individuo a la colectividad. Siguiendo su pensamiento, cada miembro del Estado ocupa el lugar que le corresponde por poseer ciertos dones, méritos y determinadas capacidades; estos tres son los que van a influir en el lugar al que van a pertenecer cada uno. El Estado es un instrumento cuyo fin último procura alcanzar la justicia.

Aristóteles construye una teoría llamada "Teoría de Mesotes", donde aplica un método de carácter geométrico y matemático que, según él, permite determinar qué es lo moralmente bueno.

Y así dice que comportarse justamente es mantenerse en el medio entre cometer y sufrir una injusticia; es una virtud; es el punto medio entre dos extremos, entre dos vicios.

Encontramos dos concepciones de la justicia como virtud. Por un lado, se concibe la justicia como virtud general del equilibrio de todas las fuerzas del alma, sobre todo del dominio de la razón sobre las pasiones. Por el otro, se estima la justicia como una virtud particular, como la constante y perpetua voluntad de atribuir cada cual lo suyo... Otra virtud emparentada con la justicia es la caridad que implica el amor al prójimo. ${ }^{22}$

En el libro V de la Ética a Nicómaco, Aristóteles dice que el hombre, mediante la razón y el lenguaje, que son instrumentos de su inteligencia, logra distinguir lo justo de lo injusto. De esta manera, él distinguía la justicia en: 1) general o legal (ordena las virtudes hacia el bien común); 2) distributiva (cada uno recibe una porción adecuada a sus méritos), y 3) correctiva (urge corregir un desequilibrio con una pena o contraprestación). A su vez, esta última se subdividía en: a) conmutativa o sinalagmática (relaciones de cambio), y b) judicial (intervención del juez ante una controversia).

Para los romanos, la justicia era constants et perpetua voluntas jus suum cuique tribuendi, contemplado en el Digesto, y significa la encarnación de la imagen de un hombre justo en el juez, que pretende alcanzar una decisión justa con su pronunciamiento.

\footnotetext{
22 Goldschmidt, Werner, op. cit., p. 389.
} 
Por otro lado, en Grecia, la injusticia se relacionaba con la impiedad; toda justicia humana exige reglas de conducta, puesto que deben justificar sus actos.

Para Ulpiano, la justicia consistía en vivir honestamente, no causar daño a otro y dar a cada uno lo suyo; en cambio, para Heráclito, la justicia era la ley, el logos.

Santo Tomás hablaba de hacer el bien y no hacer el mal, y establece dos dimensiones de la misma: una es la de la justicia como virtud personal, y la otra es la de la justicia como cualidad del orden social.

Kant, por su parte, lo expresa en su famoso imperativo categórico, en el que se pregunta lo siguiente: ¿cómo debo obrar para que mi acción sea moralmente buena? A ello responde que la acción será moralmente buena si obras según una máxima que te permita querer tu comportamiento y que pueda convertirse en ley universal.

Conforme al paradigma del Estado democrático neoconstitucional, es decir, aquel que ofrece un fundamento a la operatividad de los derechos humanos dentro de los Estados, un acto será justo cuando respete el contenido que proyectan los derechos fundamentales.

En la teoría positivista se le concibe al juez como una máquina de dar a cada uno lo suyo, darle el mismo trato a todos de manera igual. De esta manera, se aplica la regla de la igualdad, donde lo que vale para una determinada situación valdrá para otra análoga, independientemente de los intervinientes.

Un claro ejemplo de esto lo encontramos en la estatua de la justicia, en la cual una mujer, sosteniendo una balanza, posee recubiertos los ojos con una venda, lo que representa la idea de que a la justicia no le interesa que personas intervienen, a quien juzga, si es amigo o enemigo, si son adinerados o pobres. Se juzga a personas cuyas conductas recaen en una categoría jurídica determinada.

Se trata de una concepción formal de la justicia donde se aplica el silogismo, sin que nada pueda desviar ese razonamiento casi perfecto que realiza el magistrado. Lo que se busca con este rigorismo es dar la imagen de un Estado en el que se cumple de manera estricta con el principio de seguridad jurídica y de igualdad.

De esta forma, lo que pretendía el positivismo era un ordenamiento jurídico tan organizado, tan completo, y cuyas normas fueran tan claras, que concebían al conjunto normativo perfecto y sin necesidad de buscar la interpretación en otro lugar que no fuera la intención del legislador al dictar la norma. 
Aquí, el juez va a decir que algo es justo cuando sea conforme a la ley, y no cabe la posibilidad de que se cuestione la injusticia de la misma frente a un caso concreto, desarrollando un rol estático en la sociedad más que dinámico.

No podemos dejar de mencionar que en el siglo XIX se crea la teoría de los valores, que tiene por objetivo analizar la estructura, los contenidos y las relaciones que se establecen entre los distintos valores.

Hay una justicia formal, que — para Perelman — es la igualdad ante la ley, y una justicia relativa, que es la que está en los ordenamientos jurídicos, en el estado de paz y en la seguridad.

Por su parte, Goldschmidt ${ }^{23}$ plantea que

...la investigación de la justicia como valor, lleva inexorablemente el análisis al objeto valorado por la justicia o sea su material estimativo. El objeto sobre el cual recae la valoración de justo e injusto, son el orden de conductas de reparto, de potencia e impotencia y las razones de las mismas. El sustentáculo del mundo jurídico es el orden de conductas de reparto de potencia e impotencia y sus razones [y que] este orden de repartos razonados constituye el objeto de valoración jurídica.

Para los objetivistas, y entre ellos los utilitaristas, una acción es más justa cuando mayor sea el placer que cause y cuando menor sea el padecimiento que sus consecuencias hayan provocado. En cambio, para los subjetivistas, la justicia depende del juicio del observador, ya sea individual o de un grupo.

Para Guibourg: "la justicia es la situación en la que cada uno no usa los medios que se espera que no use y no sufre otras interferencias que las que se espera que sufra, todo de acuerdo con cierta estructura de poder sacralizada por el acatamiento o bien postulada desde un grupo distinto". ${ }^{24}$

También se ha dicho que "El principio supremo de justicia comprende dos elementos: el humanismo y la tolerancia". ${ }^{25}$ El humanismo busca desarrollar la personalidad de los individuos. Existe un humanismo intervencionista, donde se indica el camino a seguir y lo que conviene o no, y

23 Goldschmidt, Werner, La teoría tridimensional del mundo jurídico, El Derecho, 1962, t. III, p. 1088.

24 Guibourg, Ricardo, La construcción del pensamiento: decisiones metodológicas, Buenos Aires, Colihue, 2004, p. 123.

25 Goldschmidt, Werner, Introducción filosófica al derecho..., cit., p. 439. 
uno abstencionista, donde se da un ámbito de libertad para el desarrollo de la personalidad y de libre elección. Por su parte, la tolerancia implica que cada uno posee una verdad que no debe ser impuesta a otros seres humanos. Por el contrario, todos pueden convivir y aceptar que hay criterios distintos, a través de los cuales los sujetos llegan a diferentes verdades y todas son igualmente válidas.

No podemos dejar de hacer una breve reseña a la Teoría de la justicia de Rawls, en la cual analiza la justicia social en una sociedad donde hay una obediencia total a las instituciones y donde se comparten principios básicos de justicia.

Los principios de justicia son aquellos que establecen ciertos criterios para asignar derechos y deberes en las instituciones básicas de la sociedad y definen la distribución apropiada de los beneficios y las cargas de la cooperación social.

Se adopta una posición acerca de la justicia relacionándola directamente con la equidad (justice as fairness), en donde, según ella, los principios de justicia constituyen los principios que elegirían hombres libres y racionales que se preocupan por su propio interés si estuvieran en una posición de igualdad.

Se desarrolla, a su vez, lo que se llama "circunstancias de justicia", o sea, circunstancias que hacen que tenga sentido ocuparse de la justicia; en este sentido, se dice que no debe existir una extrema escasez de bienes ni sobreabundancia de los mismos, sino que se debe encontrar el punto medio.

Una sociedad estará bien organizada cuando sus miembros tengan como objetivo promover el bienestar general, compartan ciertos principios de justicia que todos acepten y que, a su vez, el Estado también, a través de sus instituciones, satisfaga estos principios. Por tanto, estas instituciones serán justas cuando no hagan distinciones arbitrarias entre ciudadanos y mantengan un equilibrio entre los derechos y los deberes.

"Bien común" es un término equivalente al término "justicia". Gobernar con miras al bien común, y gobernar con justicia significa una y la misma cosa. Lo que pasa es que el término "bien común" indica cierta dirección a la justicia, la de tener en cuenta los intereses de todos y no sólo los de algunos, o sea, el bien particular. ${ }^{26}$

26 Ibidem, p. 385. 
Esto tiene íntima relación con los principios en el neoconstitucionalismo; si bien el juez, a la hora de fallar, se detendrá a analizar lo que más conviene para el caso concreto, recurrirá a flexibilizar las normas seleccionadas a través del principio de equidad, del pro homine y del bien común entre otros, de tal manera que su decisión respete el contenido de los derechos humanos.

Por su parte, $\mathrm{Alexy}^{27}$ dice lo siguiente:

El conflicto entre la justicia y la seguridad jurídica debería poder solucionarse en el sentido de que el Derecho positivo asegurado por el estatuto y el poder tenga también preferencia cuando sea injusto e inadecuado en cuanto al contenido, a no ser que la contradicción entre la ley positiva y la justicia alcance una medida tan insoportable que la ley deba ceder como "Derecho injusto" ante la justicia.

Esto implica que las leyes positivas van a carecer de validez si la contradicción con la justicia es de suma importancia, lo que Alexy llama "fórmula de la intolerancia"; por otro lado, se niega la naturaleza jurídica de la norma en caso de que el legislador haya negado la igualdad al crearla, lo que denomina "fórmula de la negación".

"Las normas promulgadas conforme al ordenamiento y socialmente eficaces pierden su carácter jurídico o su validez jurídica cuando son extremadamente injustas... La extrema injusticia no es Derecho". ${ }^{28}$

En nuestra opinión, no hace falta que la injusticia sea extrema para que no sea válida, basta con realizar el control de convencionalidad y determinar si se está transgrediendo una disposición de los pactos de derechos humanos o de la interpretación que la Corte Interamericana ha realizado del Pacto de San José, para que ese acto emanado del Estado se considere como injusto y arbitrario.

En este sentido, Isidoro Eisner ${ }^{29}$ señala lo siguiente:

El fallo justo es una aspiración del Estado y de la misma colectividad, que ve en el derecho un constante quehacer en pos de los valores de la justicia. Para que el fallo sea intrínsecamente justo es necesario que la norma jurí-

27 Alexy, Robert, "Una defensa de la fórmula de Radbruch", Anuario da Facultade de Dereito da Universidade da Coruña, núm. 5, pp. 75 y 76.

28 Ibidem, p. 76.

29 Eisner, Isidoro, El principio de inmediación, Buenos Aires, Depalma, 1963, p. 14. 
dica aplicada sea bien escogida, y que ella misma - fuera de su legalidad formal— conforme al sentimiento de justicia innato en el pueblo.

Si la sentencia no aplicare la norma debida, ella será ilegal, es decir, no ajustada a derecho.

$\mathrm{Si}$, por el contrario, la ley que fundamenta el fallo fuera la que corresponde al supuesto de hecho, pero tal ley no satisface las aspiraciones de justicia y equidad, en tal caso podrá decirse que estamos frente a una sentencia legal pero no frente a una sentencia justa.

Sin embargo, esta visión ha sido superada por el nuevo paradigma neoconstitucional, que considera a las sentencias que no respeten los derechos fundamentales como decisiones no derivadas de la razón; por lo tanto, su arbitrariedad permite atacar su legalidad.

En efecto, Devis Echandía ${ }^{30}$ ya decía que "La solución justa no debe buscarse solamente en el texto escueto de la Ley sino también en los principios generales que inspiran el ordenamiento jurídico positivo de cada país".

Sumado a lo expuesto, y tal como hemos expresado ut supra, hoy se reconocen principios en la comunidad internacional que deben ser tomados en cuenta por los jueces para dictar sentencia, como el ius cogens y el pro homine, para decir que estamos frente a una sentencia justa.

El juez, con su decisión, debe haber alcanzado la justicia del caso concreto, y sólo podrá decirse que actuó con justicia cuando respetó el contenido íntegro de los derechos humanos, y esto lo logra utilizando los principios como una garantía de que no hay una aplicación impersonalizada de la ley.

El sentido de la utilización de los principios es el de humanizar las normas para realizar los valores fundantes de las Constituciones de los Estados y de los tratados de derechos humanos, acercándonos así a una solución más justa que aquella que no los utiliza.

Sin lugar a dudas, la justicia siempre fue un valor en torno al cual gira toda la actividad estatal; no obstante, en el paradigma del Estado de derecho neoconstitucional, la justicia es eje central, por cuanto será la vara con la que se mida la legalidad de los actos emanados del Estado.

De este modo, las decisiones judiciales portarán este valor y serán válidas en tanto sean congruentes con lo dispuesto por las cláusulas de derechos fundamentales.

30 Devis Echandía, Hernando, Nociones generales de derecho procesal civil, Madrid, Aguilar, 1966, p. 38. 


\section{LOS PARADIGMAS EN LA RESOLUCIÓN DE CASOS}

De acuerdo con Lorenzetti, podemos plantear la división de los casos en:

1) Todos son fáciles: se resuelven aplicando directamente el método deductivo.

2) Todos son difíciles: todos se resuelven con base en principios.

3) La regla son los casos fáciles, y los difíciles, la excepción: por lo tanto, se aplica como regla el método deductivo, salvo que no se pueda determinar qué norma aplicar o existan dudas respecto a la prueba de los hechos, por lo que se recurrirá a la argumentación a fin de resolver el asunto.

Siguiendo con lo expuesto por el actual ministro de la Corte Suprema de Justicia de la Nación Argentina, el primer paso para resolver un litigio es preguntarse si existe una norma que sea aplicable al caso presentado; de ser así, ésta debe ser aplicada inmediatamente, ya que si no se obtendría una sentencia que podría ser calificada como contra legem.

En ocasión de ello, la Corte Suprema Argentina ha dicho que "cuando la letra de la ley no exige esfuerzo de interpretación debe ser aplicada directamente" 31 y "que hay que tener en cuenta que la ley no es una mera opinión individual de las personas que las pronunciaron", ${ }^{32}$ además de que "la ley es la primera fuente de interpretación, de la que no cabe prescindir". ${ }^{33}$

Entonces, para el primer supuesto (que todos los casos sean fáciles) se debería aplicar directamente el método deductivo, que más adelante desarrollaremos.

Para el segundo supuesto, relativo a que todos los casos son difíciles y no se puede aplicar el método deductivo, pues no hay una norma que los contemple o es confuso el proceso de selección de la norma, se deben aplicar los principios generales del derecho para alcanzar la solución más justa.

Para el tercer supuesto (la regla son los casos fáciles, y los difíciles, la excepción) se da una combinación de los anteriores, aplicándose el método deductivo a los fáciles y los principios generales del derecho a los difíciles.

\footnotetext{
31 CSJN, Argentina, 324: 1740.

32 CSJN, Argentina, 77: 319.

33 CSJN, Argentina, 314: 1018, 324: 2780.
} 
Para saber cómo se utiliza el método deductivo, diremos que hay que seguir los siguientes pasos:

El primer paso es delimitar los hechos relevantes, el presupuesto fáctico, es decir, los que han sido probados conforme a las pautas probatorias establecidas en la ley, lo cual constituye la premisa menor, y esto es de tal importancia, pues, en caso de no seguirse, la sentencia puede ser atacada por arbitrariedad fáctica.

El segundo paso implica identificar dentro del ordenamiento jurídico una norma jurídica donde encuadre la premisa menor, y de esta manera ser aplicada. Este paso es tan importante como el anterior, ya que, si se aplica una norma inaplicable o inexistente, la resolución judicial puede ser atacada por arbitrariedad normativa.

Por último, considerando los dos anteriores pasos y con la aplicación del método deductivo, se alcanzará la solución para el caso concreto.

La tarea del magistrado no termina allí, ya que las partes, al llevar el pleito a los estrados judiciales, lo hacen con la convicción de que la solución que van a obtener será igual que la aplicada para casos con elementos similares, porque rige la garantía de igualdad ante la ley y el principio de seguridad jurídica. Por lo tanto, el juez deberá evaluar si para casos resueltos con anterioridad y similares se ha aplicado esa norma o el criterio de solución es otro (elemento de consistencia).

En caso de apartarse, el juez debe hacerlo fundadamente, porque está cambiando el criterio de juzgamiento y alterando el principio de seguridad citado anteriormente, que es uno de los pilares en el que se fundamenta nuestro derecho.

Respecto a esto, la Corte Nacional Argentina ha manifestado que "la regla general a seguir por los jueces, es aquella que respeta los precedentes judiciales, asegurando de esa manera la estabilidad de su jurisprudencia, y salvo casos excepcionales no debe modificarse". ${ }^{34}$ También esta Corte ha dicho que "una sentencia donde no se encuentran los fundamentos de porque se ha apartado de la doctrina aplicable, se considera arbitraria". ${ }^{35}$

Si bien hay un deber moral de seguimiento de la jurisprudencia de la Corte, ésta debe seguirse, pero no ata la decisión del magistrado, quien puede resolver fundadamente en otro sentido cuando encuentre la justicia del caso en una solución diferente.

\footnotetext{
34 CSJN, Argentina, 183: 409; 209: 431; 323: 555.

35 CSJN, Argentina, 313: 372.
} 
Por otra parte, también es necesario que el juez analice si la solución que brinda esa norma para el caso es coherente (elemento de coherencia) con el resto del ordenamiento jurídico. La coherencia se presume; por lo tanto, si se aparta de ella, el magistrado debe argumentarlo.

Por último, el juez debe medir la repercusión que causará su solución (elemento consecuencialista), ya que en ciertos casos no sólo afectará a las partes en litigio, sino que también excederá de esa esfera, ya sea a las esferas jurídica, económica o social.

Resulta que, como venimos sosteniendo, hoy no podemos hablar de casos fáciles y de casos difíciles; esto parece haber quedado superado, porque ya nada se puede resolver con el método deductivo.

Este método ya no es suficiente para dar respuesta a las exigencias sociales actuales ni para resolver conforme al nuevo paradigma que exige respeto por el contenido de los derechos humanos.

En la actualidad, se necesitan jueces que vayan más allá de la norma, interpretando el derecho en su sentencia con los principios que rigen en la comunidad internacional. La decisión no puede basarse sólo en la ley, pues hay requerimientos de cumplimiento ineludible y que hacen efectivo el acceso a la justicia.

Hoy podemos afirmar que todos los casos son difíciles, porque en todos se presentan complicaciones con la norma a aplicar, y porque hay que integrarla con principios y buscar que la solución realice los valores socialmente reconocidos y protegidos.

La argumentación, como respuesta a esta insuficiencia normativa, es aceptada porque la decisión, sea cual sea, puede ser explicada en términos lógicos y razonables como un todo coherente, siguiendo una línea de pensamiento determinada pausible de ser verificada. ${ }^{36}$

Algunos podrán alegar que esto apareja un problema mayor: cuál es la de libre interpretación del juez sobre la norma, lo que conllevaría a una inseguridad jurídica.

Justamente, para limitar tal situación se ha dado creación a los principios jurídicos, los que pretenden ser la luz que guíe al juez en la búsqueda de la solución más justa para el caso concreto. Sobre todo, el principio que debe procurar ser luz en cualquier decisión judicial es el pro homine,

36 Para ampliar, véase Redondo, María Belén, "La fundamentación de la sentencia en el Código Civil. Una referencia al derecho de acceso a la justicia”, en Fernández Balbis, Amalia y Peyrano, Marcos (dirs.), Derivaciones procesales del Código Civil y Comercial, Rosario, Nova Tesis, 2017. 
porque se constituye en la directriz que permite otorgar derechos más amplios, respetando por encima de todo la dignidad humana.

Respecto a la colisión normativa que se da cuando las normas son contrarias, es decir, una norma prohíbe y la otra manda a hacer, y son normas que refieren al mismo ámbito temporal y espacial, el problema puede resolverse del siguiente modo:

- La norma posterior deroga la anterior.

- La norma superior se impone sobre la inferior.

- La norma especial desplaza la general.

Sumado a ello, se ha destacado la importancia de tener en cuenta la expresión in dubio pro ratione, la cual implica que "en caso de duda hay que optar por la solución más racional". ${ }^{37}$

Nosotros agregamos, tal y como ya hemos mencionado, el principio pro homine, al que podemos definir como aquella directriz que permite otorgar, a la luz del caso concreto, la solución más amplia y con mayores beneficios a las personas.

Por su parte, definiremos también al principio de ius cogens como aque1la directriz que, por tener naturaleza de principio de orden público internacional, posee per se una fuerza arrolladora, a través de la cual tiene como objetivo mantener incólume la igualdad, la no discriminación y la efectivización del derecho de acceso a la justicia, con todas las aristas que de este derecho se desprenden, tales como el plazo razonable, el derecho a ser oído, contar con recursos idóneos y efectivos, el control de la prueba, la simplicidad y justicia comprensible, y la buena fe; por esta razón, todo acto estatal o de la comunidad internacional que se le oponga será nulo, de nulidad absoluta $a b$ initio.

Respecto a la solución de los litigios conforme a la elección de un determinado paradigma, puede aparejar problemas, ya que no se respeta la igualdad ante la ley, porque dos magistrados pueden optar por paradigmas diferentes frente al mismo caso, y, a su vez, la Corte ha censurado en reiterados casos la interpretación subjetiva. ${ }^{38} \mathrm{El}$ beneficio es que entre los que comparten el mismo paradigma es más fácil debatir y llegar a una solución común.

37 Lorenzetti, Ricardo, Teoría de la decisión judicial. Fundamentos de derecho, Santa Fe, Rubinzal-Culzoni, 2008, p. 267.

38 CSJN, Argentina, 306: 1428; 313: 1232. 
Siguiendo a Lorenzetti, podemos clasificar a los paradigmas para la decisión en:

1. Paradigma de acceso a los bienes jurídicos primarios. Por medio de este se propone tutelar a los excluidos, a los que no pueden acceder a los bienes jurídicos primarios; se basa en la garantía constitucional consagrada en el artículo 16, que se refiere a la igualdad ante la ley y la igualdad de oportunidades.

Se busca combatir la desigualdad social, que se produce cuando en el desarrollo de la comunidad ciertos sectores quedan relegados del goce de los bienes elementales para su subsistencia.

Entre estos derechos, podemos encontrar el de salud y el de educación, que deben garantizarse por parte del Estado, sin discriminación alguna con base en un criterio de justicia distributiva.

2. Paradigma protectorio. Se propone tutelar a los vulnerables, proteger a los individuos de un Estado; se basa en la igualdad, por ejemplo, la interpretación a favor del deudor o del consumidor, así como del trabajador o del reo.

La vulnerabilidad puede darse porque existe una insuficiencia en la información o por cuestiones de competencia, como el monopolio, técnicas al no poseer la persona conocimiento específico sobre el bien que adquiere, o por una cuestión económica, tratándose del caso de los trabajadores.

3. Paradigma colectivo. Se tutelan las relaciones grupales y los bienes colectivos; se le da preeminencia a éstos sobre los individuales, porque afectan a la sociedad y permite la convivencia armoniosa de una comunidad. Entre estos bienes, podemos citar el patrimonio histórico o cultural, el medio ambiente y la salud.

4. Paradigma consecuencialista. Éste paradigma propone un análisis de las consecuencias públicas que aparejan las acciones privadas, dando lugar a la demarcación de los límites para hacer posible la vida en común.

5. Paradigma del Estado de derecho constitucional. Dicho paradigma establece un límite al poder político y a las decisiones de la mayoría; pregona el respeto por los derechos humanos, considerados como previos a la Constitución de los Estados, y limita la centralización del poder político a través de acciones de participación de la sociedad y jueces como guardianes de la carta magna.

6. Paradigma ambiental. Para éste, el sujeto principal es la naturaleza, que se encuentra actualmente en peligro, y por ello se propone limitar el ejercicio de los derechos individuales en aras de la protección del mismo, 
ya que traerá un beneficio a toda la humanidad. Dicho paradigma llega a considerar que los derechos individuales tienen una función ambiental.

El juez puede tomar varios paradigmas para resolver una cuestión, no necesariamente debe abocarse a un determinado paradigma.

Es mucho más completa e integrada la visión que le puede dar la combinación de varios y tomar de cada uno las normas que más protegen a las partes en el litigio y a las garantías del proceso.

De todas maneras, creemos que estos paradigmas brindan pautas que se pueden reunir en uno solo y más completo, al que denominamos "paradigma del juez humanista integrativista".

Este modelo de juez tendrá en cuenta los aspectos no sólo constitucionales y del ordenamiento interno, sino que también aquellos principios que rigen en la comunidad internacional y que son aplicables a lo largo del proceso y que surgen para lograr una tutela efectiva de las garantías judiciales.

Este paradigma va más allá del paradigma constitucional de derecho, puesto que no se limita a enunciar derechos como forma de restringir el poder del Estado, sino que es una actividad que se preocupa por las deficiencias del sistema judicial y legislativo actual y busca soluciones para establecer mecanismos reales de efectivización de derechos.

Asimismo, se aboca a las políticas públicas delineadas por el Poder Ejecutivo, con el objeto de que de manera coordinada se adopten medidas integrales para la protección de los derechos fundamentales.

El paradigma de la decisión en la era del neoconstitucionalismo ya no sólo toca la arista del Poder Judicial al resolver los casos presentados en sus estrados, sino que también de manera conjunta influye necesariamente en la legislación que se crea en los congresos y en el modelo de Estado que adopta el Poder Ejecutivo a través de la ratificación de los pactos de derechos humanos.

\section{EL NUEVO PARADIGMA DE LA DECISIÓN: “EL JUEZ HUMANISTA INTEGRATIVISTA"}

El nuevo paradigma parte del supuesto de una realidad como fenómeno complejo, y es por ello que las respuestas que deba dar sean también de este tenor.

De tal guisa, debe comenzarse a razonar desde el integrativismo y no desde el derecho como norma solamente, sin estancar al derecho; por el contrario, hay que dinamizarlo. 
El concepto de lo que hoy se considera como justo toca diversas aristas, con lo cual debe decidirse conforme a la complejidad, a la realidad y a la equidad.

Hay que superar la idea de Juez dogmático y enriquecerlo, mejorarlo, haciéndolo Juez Humanista, que tiene en cuenta absolutamente todos los factores, y sobre todo que considera que las garantías procesales forman parte actualmente dentro del catálogo de Derechos Humanos, y como tal hay compromisos internacionales que no pueden dejarse de lado. ${ }^{39}$

Tal como hemos expuesto previamente, el control sobre las decisiones judiciales ya no sólo se realiza por las partes que litigan, sino que también hay una comunidad internacional de la que formamos parte y que tiene la expectativa de que estos derechos se respeten.

El rol del Estado no se limita a reconocer derechos, en especial los derechos fundamentales, los cuales actualmente se reconocen como previos al mismo por ser inherentes a la condición humana, sino que ahora es el principal garante del cumplimiento de los mismos.

Al revés del juez técnico que parte del sistema jurídico (al que considera cerrado, coherente y completo) y que, en consecuencia, no resuelve (o soluciona defectuosamente) los nuevos problemas que no están adecuadamente previstos en el ordenamiento jurídico, el juez humanista parte de los seres humanos concretos que se encuentran inmersos en un conflicto intersubjetivo (tienen un problema) y procura encontrar la mejor solución posible para ese hombre o mujer de carne y hueso (no para la persona o sujeto de derecho como abstracción) a través de un diálogo cara a cara, personal y comprometido, sin salirse del sistema jurídico, pero sin atarse acrítica e irreflexivamente a una única interpretación posible de las normas jurídicas. ${ }^{40}$

El concepto de humanista deviene de un juez que toma decisiones y dirige el proceso en su totalidad mediante el respeto la dignidad humana y la consideración de los principios que se desprenden del derecho de acceso a la justicia, efectivizando principios como el de simplicidad o de clare loqui,

39 Redondo, María Belén, "La jurisdicción preventiva en el paradigma (neo) constitucional”, en Peyrano, Jorge W. (dir.) y Esperanza, Silvia L. (coord.), La acción preventiva en el Código Civil y Comercial de la Nación, Santa Fe, Rubinzal-Culzoni, 2016, p. 183.

40 Ghirardi, Olsen et al., Diez años, Córdoba, Academia Nacional de Derecho y Ciencias Sociales de Córdoba, Instituto de Filosofía del Derecho, 2008, vol. 10, pp. 274 y 275. 
para que las partes puedan comprender por sí mismas las diversas etapas del proceso en las que están inmersas.

Asimismo, el humanismo, cuando se trata de personas en condición de vulnerabilidad, abre las puertas de la justicia a modo de efectivizar todos los aspectos que esta condición requiere, para que la persona no sufra una doble vulneración, y atendiendo a su condición específica.

En este sentido, la Corte Interamericana considera

...que toda persona que se encuentre en una situación de vulnerabilidad es titular de una protección especial, en razón de los deberes especiales cuyo cumplimiento por parte del Estado es necesario para satisfacer las obligaciones generales de respeto y garantía de los derechos humanos. La Corte reitera que no basta que los Estados se abstengan de violar los derechos, sino que es imperativa la adopción de medidas positivas, determinables en función de las particulares necesidades de protección del sujeto de derecho, ya sea por su condición personal o por la situación específica en que se encuentre. ${ }^{41}$

En cuanto al término "integrativista", éste hace alusión no sólo al conjunto de aspectos que se tienen en cuenta para resolver la contienda, sino también a todos los aspectos que puedan influenciar en su resolución, y acude a los principios superiores integrándolos con las normas para cumplir con la efectiva tutela judicial.

En contraposición a este modelo, encontramos al "juez dogmático" o llamado también "técnico", el que pretende resguardarse en el ordenamiento normativo y no salirse de él, aun cuando la solución pueda ser contraria a derecho, porque cree que de esa forma evita la arbitrariedad.

En este sentido se enrola la corriente garantista, cuyo apego a la ley es tan fuerte que en muchas ocasiones devienen en decisiones injustas por no considerar otros aspectos que sí son tomados en cuenta por la corriente activista, cuya bandera es la de la efectivización en tiempo real de los derechos, aplicando todo el sistema de derecho nacional e internacional vigente.

Para el juez técnico, la sentencia es un simple silogismo, donde existe una premisa menor (el caso concreto), una premisa mayor (la norma) que regula perfectamente lo sucedido y una conclusión, a la que se arriba sin más trámite que aplicando la norma que más se adecua a los hechos dados.

41 Corte Interamericana de Derechos Humanos, Caso Ximenes Lopes vs. Brasil, Sentencia del 4 de julio de 2006. 
El juez integrativista reconoce que el ordenamiento es imperfecto, que existen vacíos y que muchas veces, si bien hay una norma que regula el caso, la situación particular de las partes en el proceso torna inaplicable la directiva, porque de hacerlo sería extremadamente injusto.

El juez integrativista interpreta conforme a la actividad creativa que brinda la elasticidad del principio pro homine y del ius cogens, conjugándolos con la sana crítica, la experiencia, la prudencia y el resto de los principios consagrados en la comunidad internacional.

Este juez acepta que el Estado reconoce derechos, pero que muchos de ellos no son efectivizados (por ejemplo, el derecho a la salud y el derecho a la vivienda) y que son de ilusorio cumplimiento, generando desigualdades en la sociedad; frente a ello, dicho juez asume una postura activa, buscando una solución que no deje paralizados los derechos en juego.

En este modelo, la misión del juez es intentar eliminar la brecha que se genera en la comunidad por la diferencia de oportunidades; dirige protegiendo al más débil en el curso del proceso, haciendo efectiva, por ejemplo, la inversión de la carga de la prueba. Por eso, dicho juez tiene en cuenta también las diversas condiciones de vulnerabilidad que puedan surgir.

El juez humanista tiene en cuenta que los plazos de tramitación de un pleito pueden ser largos y que, por tanto, debe contribuir a dictar sentencia en un plazo razonable, porque con esta dilación puede generarse responsabilidad internacional del Estado, tal y como en numerosos casos lo ha determinado la Corte Interamericana de Derechos Humanos. ${ }^{42}$

Así, también estos jueces se valen de un lenguaje que, más allá de ser técnico, sea entendible por cualquier lego ${ }^{43}$ y que queden claras las razones que lo llevaron a fallar de una manera y no de otra.

¿Es posible este modelo de juez integrativista en el mundo? La respuesta dependerá del compromiso asumido por cada Estado, sin necesidad de mejoras estructurales, lo que debe cambiar y revolucionarse es la forma de resolver los conflictos; el giro copernicano yace exclusivamente en considerar todos los factores, en integrarlos y en resolver mediante la aplicación, sobre todo, a el bloque convencional, teniendo en cuenta las

42 Corte Interamericana de Derechos Humanos, Caso Furlán y Familiares vs. Estado Argentino, Sentencia del 31 de agosto de 2012.

43 Juzgado de Familia, Civil, Comercial, Minería y Ambiente de la Tercera Circunscripción Judicial de la localidad de El Bolsón, Argentina, M., F. L S/Adopción Plena (O3BA-161-F2015), Sentencia del 6 de septiembre de 2016. 
diversas aristas de la tutela judicial efectiva, cuya ductilidad permite y le da libertad al juez para interpretar, pretendiendo siempre alcanzar el valor "justicia".

\section{EL JUEZ DECIDE, EL CORAZÓN GUÍA}

El corazón tiene sus razones, que la razón desconoce.

Pascal BLAISE

Ya hemos expuesto nuestra postura en cuanto a que el juez no es una máquina de emitir sentencias; en consonancia con ello, nos pareció pertinente hacer algunos comentarios acerca de una nota leída sobre el estudio científico de las emociones, lo que se pretendió demostrar y la relación a la hora de fallar.

En todo rincón del planeta se jura con la mano en el corazón, se lo ofrece como prueba de amor, se lo siente estallar de tristeza o estremecerse de miedo. Se obedece a sus corazonadas. Se vitupera a los de corazón duro y se honra a los que poseen un corazón de oro. Se trata, acaso, de la metáfora más antigua, íntima y universal de todas. ¿Metáfora nada más $?^{44}$

Los magistrados utilizan, como venimos sosteniendo, a la razón como un instrumento para analizar los hechos y para buscar la norma que más se adecua a la situación, interpretarla en función de principios y, por último, fundamentar su fallo.

Pero, además de la razón, lo cierto es que el juez, a medida que va conociendo el caso, se guía por el corazón como otro instrumento que utiliza para llegar a la verdad; los pálpitos y la sensación de que el litigo se dio en la realidad de una forma y no de otra también influyen en la decisión.

Sería ingenuo negarlo y por algo la corriente filosófica del realismo lo estudia y pone como eje central de su teoría el análisis de la psicología del juez: cómo piensa, qué tipos de gustos tiene, cuáles son sus tendencias e inclinaciones.

44 Raimondi, Natalia, "Cerebro del corazón", disponible en: http://www.asociacione ducar.com/monografias/raimondi.pdf (fecha de consulta: 6 de septiembre de 2018). 
En muchas ocasiones, la voz de la experiencia, aunque las pruebas no alcancen o demuestren lo contrario, llevan al juez a tener ciertas corazonadas respecto a cómo se suscitaron los hechos en la realidad, pretendiendo alcanzar la verdad real en vez de la verdad del expediente. Es por ello que muchos códigos procesales contemplan las medidas para mejor proveer.

Es un deber impuesto por la sociedad el de ser siempre razonable al tomar una decisión, lo cual, por supuesto, es de suma importancia; pero no debemos negar la existencia de factores subjetivos que influyen en la mente humana a la hora de resolver.

Y es así como se ha dicho que

El legislador, el jurisconsulto y aun el abogado, deben tener un sistema, una orientación del pensamiento; pero cuando se presenta el pleito en concreto, su inclinación hacia uno u otro lado debe ser hija de la sensación. Claro que esta sensación es un simple reflejo de todo el cuerpo doctrinal que el jurista lleva en su alma. Por donde la sensación es aquí el vehículo de la justicia... ${ }^{45}$

En lo que respecta a lo biológico, el cerebro del humano consta de lóbulos prefrontales y es lo que nos distingue de los animales y nos permite pensar, analizar, plantearnos objetivos, y alcanzarlos; estrictamente aplicado a nuestro caso, ello nos da la posibilidad de valorar las pruebas, ordenarlas, señalar los hechos pasados, establecer una comunicación a través del lenguaje entre el juez y las partes, así como arribar a una conclusión racional.

Jorge Armony, físico egresado de la Universidad Nacional de Buenos Aires, brindó una charla titulada "Neurobiología de las emociones" en Buenos Aires, Argentina, en ocasión del Simposio Corazón-Cerebro, que fue organizado por la Fundación Favaloro y la Cleveland Clinic de los Estados Unidos en 2007.

En esa charla, Armony afirmó que cree en la posibilidad de estudiar las emociones y contó acerca de la forma en que dicha hipótesis puede comprobarse.

Colocamos a las personas en un resonador magnético y les pedimos que hagan algo, que recuerden, o les mostramos imágenes; luego, comparamos con la actividad normal... La emoción es una reacción primitiva, que ejecuta

45 Ossorio y Gallardo, Ángel, El alma de la toga, Buenos Aires, Librería El Foro, 1997, p. 39. 
la amígdala, y que el ser humano comparte hasta con las ratas... Claro que hay emociones más refinadas que son productos culturales. El orgullo y la envidia aún no se detectaron en animales. ${ }^{46}$

Con esto, podemos ver que las emociones repercuten en lo físico, activando zonas del cuerpo, lo cual quiere decir que, cuando los magistrados entienden un caso, por más objetivos que pretendan ser al razonar, la cuota de voluntad se halla inmersa en este proceso de decisión, porque cada caso repercute en las emociones de manera diferente $y$, por tanto, se abre el abanico de posibles soluciones.

Frente a esta información, ¿cómo podemos negar que la intuición acompaña al magistrado a la hora de fallar?, ¿cómo podemos pensar al juez como una máquina de subsumir casos en la norma general?

La realidad muestra otra cosa: estudios científicos dejan ver al juez como un ser humano igual que el resto, siendo falible, intuitivo y razonable, características que conviven dentro de una misma persona y que hacen a la decisión más enriquecedora.

De este modo, el nuevo paradigma le exige al juez que busque la verdad real, que se supere la verdad del expediente. Muchas veces surgen dudas, y en otras ocasiones es la experiencia o su corazonada las que le indican lo contrario a lo hasta ese momento probado; por ello, debe seguir investigando lo suficiente para estar realmente seguro de que está haciendo justicia para el caso concreto.

"Después de todo, esto es lo que los antiguos sostenían mediante el aforismo summun jus summa injuria. Lo bueno, lo equitativo, lo prudente, lo cordial no ha de buscarse en la Gaceta. Viene de mucho más lejos, de mucho más alto...". ${ }^{47}$

\section{CONCLUSIÓN}

A modo de conclusión, podemos decir que hoy en día los Estados, considerados como entes soberanos que se daban sus propias normas y en los que se veían bien demarcados sus límites, se ven afectados en su estructura debido al proceso de mundialización de los derechos humanos.

\footnotetext{
46 Raimondi, Natalia, op. cit.

47 Ossorio y Gallardo, Ángel, op. cit., pp. 39 y 40.
} 
Existe una comunidad internacional que reconoce la existencia de derechos de las personas por el solo hecho de ser seres humanos. Asimismo, se comienzan a generar compromisos internacionales a través de pactos y, por ello, los Estados deben responder con sus recursos al máximo, así como ocuparse de crear la legislación necesaria para que los derechos se efectivicen.

Se puede observar que la función judicial se ha visto modificada por este gran fenómeno denominado "globalización" en su vertiente jurídica: la de los derechos humanos, trayendo consigo un nuevo paradigma, que en este caso es el del Estado democrático neoconstitucional.

El rol del juez, que antes era el de ser la boca de la ley frente a la inexistencia de estos compromisos internacionales y la rigidez en la que se le enmarcaba debido a la gran desconfianza que se le tenía, hoy da un giro copernicano: su rol es completamente activo y debe encargarse de que los derechos se hagan efectivos y no sean meras utopías.

De este modo, el garantismo con un tinte de apego a la ley se supera para dar paso al activismo judicial, donde se permite la actividad creativa propia de la elasticidad del concepto de derecho y de los principios jurídicos vigentes.

En el Estado democrático de derechos humanos, el derecho de acceso a la justicia no se agota con la apertura de la instancia judicial; por tal motivo, requiere que en todas las etapas del proceso se hagan efectivos los principios que éste conlleva, entre los que se encuentran el del plazo razonable, la simplicidad, la justicia comprensible y el trato digno y humanitario.

Fecha de recepción: 4 de abril de 2018.

Fecha de aceptación: 24 de agosto de 2018. 